\title{
A critical assessment of the utility of protein-free splicing systems
}

\author{
DUNCAN J. SMITH and MARIA M. KONARSKA \\ Laboratory of Molecular Biology and Biochemistry, The Rockefeller University, New York, New York 10065, USA
}

\begin{abstract}
U2 and U6 snRNAs form part of the catalytic spliceosome and represent strong candidates for components of its active site. Over the past decade it has become clear that these snRNAs are capable of catalyzing several different chemical reactions, leading to the widespread conclusion that the spliceosome is a ribozyme. Here, we discuss the advances in both protein-free and fully spliceosomal systems that would be required to conclude that the reactions observed to be catalyzed by protein-free snRNAs are related to splicing and question the reliability of snRNA-only systems as tools for mechanistic splicing research.
\end{abstract}

Keywords: RNA catalysis; splicing; snRNAs

\section{INTRODUCTION}

The ability of snRNA-derived RNA sequences to catalyze chemical reactions including $2^{\prime}-5^{\prime}$ phosphodiester bond formation has previously been interpreted as strong evidence for ribozyme catalysis by the spliceosome (Tuschl et al. 2001; Valadkhan and Manley 2001; Valadkhan et al. 2007). In an accompanying report, we characterize a short 2 '-3' bond-forming ribozyme activity in the linker region of a fused snRNA construct originally conceived to establish a protein-free splicing system based on Saccharomyces cerevisiae snRNAs; this highlights the inherent reactivity of RNA molecules and the broad catalytic repertoire open even to seemingly random RNA sequences. In addition, this work has led us to reevaluate this approach to the mechanistic investigation of splicing. In order for experimental systems based entirely on RNA to live up to their stated promise as the basis for analysis of splicing catalysis, they must be fully validated. Given that catalytic mechanisms cannot be proven but only disproven, such validation requires that protein-free systems be shown, as far as possible, to catalyze reactions identical to those of splicing both in terms of chemistry and catalytic mechanism. Both stringent characterization of intermediates and products

Reprint requests to: Maria M. Konarska, Laboratory of Molecular Biology and Biochemistry, The Rockefeller University, 1230 York Avenue, New York, NY 10065, USA; e-mail: konarsk@mail.rockefeller.edu; fax: (212) 327-7147.

Article published online ahead of print. Article and publication date are at http://www.rnajournal.org/cgi/doi/10.1261/rna.1322709. and the concordance of results between protein-free and complete spliceosomal systems are therefore required. The need for recapitulation of results from RNA-only reactions highlights in turn the pressing need for model systems in which the catalytic phase of splicing can be studied in a truly spliceosomal context.

\section{DEFINING AND VALIDATING RELATEDNESS TO SPLICING}

RNA is a structurally promiscuous polymer that contains diverse functional groups: as such, a single RNA sequence may have the potential to catalyze and/or participate in many reactions (Lorsch and Szostak 1996). Because sensitive detection methods allow for the investigation of products formed in low yields and at slow rates, multiple products may appear on extended incubation of diverse RNA molecules (including but not limited to RNAs that are snRNA derived). Thus, early in the development of a minimized model system for pre-mRNA splicing, it may be necessary to decide which reaction product one defines to be derived from a splicing-related reaction. RNA-only systems that generate products with the same covalent linkages as those that result from spliceosomeal splicing merit study and could serve as interesting models for RNA catalysis. A shared chemical identity, however, does not necessarily indicate that the precise mechanisms by which two bonds are formed are identical. The present definition of relatedness to splicing and our incomplete knowledge of contributors to spliceosomal catalysis make it unclear 
whether conclusions drawn from protein-free splicing are truly applicable to the spliceosome.

Relatedness of a ribozyme reaction to pre-mRNA splicing has conventionally been concluded from its sensitivity to mutation of the ACAGAGA and/or AGC motifs in the U6 snRNA (or its derivative) component of the reaction (Tuschl et al. 2001; Valadkhan and Manley 2001; Valadkhan et al. 2007). Sensitivity to such mutations is, however, not necessarily indicative of direct similarity to either reaction of splicing. Although these core motifs, which are shared between U6 snRNA and group II introns, have recently been demonstrated to form the basis of the group II intron active site (Toor et al. 2008), similar sequences are also found in other ribozymes believed to be unrelated to snRNAs, and the full details of the role(s) of ACAGAGA and AGC in both these ribozymes and the spliceosome remain unclear. For example, in spite of its universal conservation, the AGC triad is remarkably mutable in $S$. cerevisiae, with all substitutions except A59U and G60Y viable either alone or in the presence of compensatory $\mathrm{U} 2$ snRNA mutations that restore a helical interaction (helix Ia) (Hilliker and Staley 2004). Backbone groups, rather than bases, coordinate metal ions; the results of sequencebased mutagenesis could reflect structural defects common to various RNA folds and must therefore be treated with caution.

Group II self-splicing introns provide a natural precedent for RNA catalysis of the two chemical reactions of pre-mRNA splicing, and their well-established similarities and likely evolutionary relatedness to snRNAs (Pyle 2008), especially in light of the recent group II intron crystal structure (Toor et al. 2008), provide strong support for the hypothesis that the spliceosome active site is at least partially RNA based. We note that, by the present definition of relatedness to splicing, group II introns qualify as a proteinfree splicing system. We therefore suggest that either group II introns provide a preexisting and ideal protein-free system in which mechanistic studies of pre-mRNA splicing can be carried out or that more stringent requirements must be applied for a reaction to be considered as sufficiently related to spliceosomal splicing to serve as a model: one requirement is similar dependence on divalent metal ions. Magnesium has been directly demonstrated to be important for spliceosomal catalysis (Sontheimer et al. 1999; Gordon et al. 2000), and further investigation should clarify the coordination and precise mechanistic roles of divalent ions in the spliceosome. Mechanistically similar metal ion dependence in protein-free systems must be considered a prerequisite for splicing relatedness.

Before sensitivity to the mutation of core motifs in U6 snRNA can be used to define a splicing-like reaction, the nature of the defects arising from such mutations within a truly spliceosomal context must be elucidated. Subsequent work demonstrating that defects are mechanistically identical in spliceosomal and protein-free contexts would, we believe, provide evidence that the observed reaction resembled splicing. Again, however, we note that this mechanistic identity may already exist between group II introns and the spliceosome.

\section{THE SPLICEOSOME AS AN RNP}

The above discussion highlights the need to develop parallel, fully spliceosomal model systems for the study of splicing catalysis before the applicability of protein-free reactions (including those of group II introns) to splicing can be reliably assessed. The protein component of the spliceosome should not be ignored despite its daunting complexity (Jurica and Moore 2003). A large number of spliceosomal proteins are essential for cellular viability and splicing in vitro: while many play important roles in the conformational rearrangements required for productive splicing (for review, see Smith et al. 2008), a growing body of evidence suggests that some spliceosomal proteins have a function beyond simple scaffolding of a catalytic RNA core. Several recent studies show that Prp8 has an RNase H fold, also found in integrases and transposases (Pena et al. 2008; Ritchie et al. 2008; Yang et al. 2008). This domain has previously been shown to contact the $5^{\prime}$ SS and binds a structured RNA reminiscent of proposed intron-snRNA complexes. Although the residues corresponding to the RNase $\mathrm{H}$ active site do not conform to the consensus or bind metal ions in any of these crystal structures, a similar active site arrangement can be found in catalytically active RNase $\mathrm{H}$ domains, as noted by MacMillan and colleagues (Ritchie et al. 2008, and references therein). This raises the possibility that Prp8 may directly participate in one or both steps of splicing catalysis. Regardless of Prp8's direct contribution to catalysis, we believe that the intimate involvement of this and other proteins means that, even if the metal ions required for splicing catalysis are coordinated entirely by groups from snRNAs, the spliceosome should still be considered an RNP with an RNA active site, rather than a ribozyme.

Substantial further progress in the mechanistic splicing field will require experimental models in which the catalytic phase of splicing can be investigated. In this regard, knowledge of the catalytic abilities and limitations of both snRNAs and spliceosomal subcomplexes could provide important information about structural requirements for the catalytic reactivity of RNA and lay useful groundwork for progress in terms of spliceosome minimization and/or reconstitution. We stress, however, the need for caution in extending the interpretation of such work into mechanisms of RNP action in the context of biological processes.

Although snRNA-only splicing cannot demonstrate that the spliceosome is a ribozyme, a validated system might rapidly produce a number of hypotheses regarding spliceosomal catalysis. Given the importance of spliceosomal 
proteins, the parallel systems able to validate protein-free splicing and test these hypotheses would by necessity be based on at least predominantly intact spliceosomes. Thus, while we believe that protein-free splicing may raise interesting questions, the hypotheses it generates will remain unvalidated until they are supported by data from a model that supersedes the snRNA-only reaction. For this reason, we believe that the establishment of more complete spliceosomal models represents the most constructive avenue for future research.

\section{ACKNOWLEDGMENTS}

We thank Christine Guthrie, Charles Query, Jon Staley, Tom Tuschl, and other colleagues for constructive comments and helpful discussions.

\section{REFERENCES}

Gordon, P.M., Sontheimer, E.J., and Piccirilli, J.A. 2000. Metal ion catalysis during the exon-ligation step of nuclear pre-mRNA splicing: Extending the parallels between the spliceosome and group II introns. RNA 6: 199-205.

Hilliker, A.K. and Staley, J.P. 2004. Multiple functions for the invariant AGC triad of U6 snRNA. RNA 10: 921-928.

Jurica, M.S. and Moore, M.J. 2003. Pre-mRNA splicing: Awash in a sea of proteins. Mol. Cell 12: 5-14.
Lorsch, J.R. and Szostak, J.W. 1996. Chance and necessity in the selection of nucleic acid catalysts. Acc. Chem. Res. 29: 103-110.

Pena, V., Rozov, A., Fabrizio, P., Luhrmann, R., and Wahl, M.C. 2008. Structure and function of an RNase $\mathrm{H}$ domain at the heart of the spliceosome. EMBO J. 27: 2929-2940.

Pyle, A.M. 2008. Group II introns: Catalysts for splicing, genomic change and evolution. Royal Society of Chemistry, London.

Ritchie, D.B., Schellenberg, M.J., Gesner, E.M., Raithatha, S.A., Stuart, D.T., and MacMillan, A.M. 2008. Structural elucidation of a PRP8 core domain from the heart of the spliceosome. Nat. Struct. Mol. Biol. 15: 1199-1205.

Smith, D.J., Query, C.C., and Konarska, M.M. 2008. "Nought may endure but mutability": Spliceosome dynamics and the regulation of splicing. Mol. Cell 30: 657-666.

Sontheimer, E.J., Gordon, P.M., and Piccirilli, J.A. 1999. Metal ion catalysis during group II intron self-splicing: Parallels with the spliceosome. Genes \& Dev. 13: 1729-1741.

Toor, N., Keating, K.S., Taylor, S.D., and Pyle, A.M. 2008. Crystal structure of a self-spliced group II intron. Science 320: 77-82.

Tuschl, T., Sharp, P.A., and Bartel, D.P. 2001. A ribozyme selected from variants of U6 snRNA promotes $2^{\prime}, 5^{\prime}$-branch formation. RNA 7: 29-43.

Valadkhan, S. and Manley, J.L. 2001. Splicing-related catalysis by protein-free snRNAs. Nature 413: 701-707.

Valadkhan, S., Mohammadi, A., Wachtel, C., and Manley, J.L. 2007. Protein-free spliceosomal snRNAs catalyze a reaction that resembles the first step of splicing. RNA 13: 2300-2311.

Yang, K., Zhang, L., Xu, T., Heroux, A., and Zhao, R. 2008. Crystal structure of the $\beta$-finger domain of Prp8 reveals analogy to ribosomal proteins. Proc. Natl. Acad. Sci. 105: 1381713822 . 

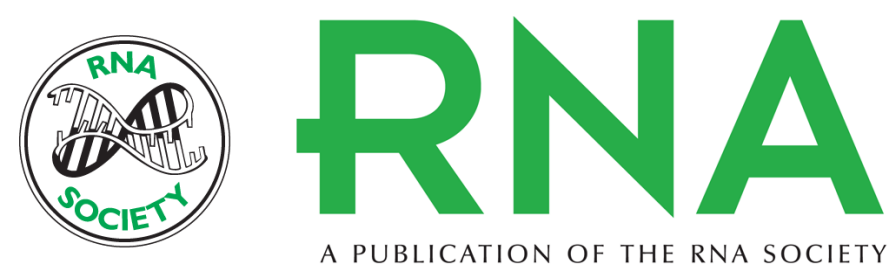

A PUBLICATION OF THE RNA SOCIETY

\section{A critical assessment of the utility of protein-free splicing systems}

Duncan J. Smith and Maria M. Konarska

RNA 2009 15: 1-3 originally published online November 24, 2008

Access the most recent version at doi:10.1261/rna.1322709

\section{References This article cites 13 articles, 7 of which can be accessed free at: http://rnajournal.cshlp.org/content/15/1/1.full.html\#ref-list-1}

\section{License}

Email Alerting Receive free email alerts when new articles cite this article - sign up in the box at the Service top right corner of the article or click here. 